\title{
The Value of Less and Small: Transforming Metropolitan Doha into Connected, Human and Resilient Urban Settlements TITLE \\ Subtitle
}

Ali ALRAOUF, Prof. of Architecture and Urbanism; Qatar

\begin{abstract}
Qatar is one of few Middle Eastern oil producing countries that realized the vitality of a needed swift transformation from resources to knowledge economy. Until a few decades ago, Qatar was dominated by nomadic people whose livelihood depended on fishing, pearling, camel breeding, and fishing ships building. However, the discovery of oil and gas has encouraged not only socio-economic change, but environmental change as well. The discussed account will cover the main strategies adopted by the country to create a distinctive model of development in the Middle East. The study also analyzes the shift over the past decade which reveals how Qatar views investments in knowledge-based urban development as essential vehicles to survive in a globalized and competitive world. More significantly, the study illustrates an interesting form of urban resilience in the face of major challenges which faced Qatar in the last decade including, winning the bid to host the FIFA World Cup 2022, the decline of oil prices and the air, sea and ground blockade imposed by its adjacent neighbors. The study sheds light on different urban planning strategies and policies adopted to shift the focus from creating a mega city with an image which resonate with typical global cities to a more sustainable, resilient, knowledge-based and decentralized urbanity. The model of Qatar is analyzed holistically in the paper to go form the strategic planning decisions all the way to case studies and best practice planning projects. The study demonstrates how Qatar has captured the world's imagination by balancing global aspirations and local necessities in a sustainable and resilience context. This paper examines a framework for city and urban regions inspired by the theory of placemaking and its relevance to the boundaries of human urbanism. The paper sheds new light on the transformation of the city from a metropolitan exploiting the oil and gas revenues to a multi-centered model of urbanism. In doing so, the city adopted a number of significant strategies include the well distributed livable urban centers, transit-oriented development, introducing compacted urbanism and encouraging models of mixed use development. The paper concludes with a planning matrix which suggest that for Qatar, adopting such strategies and the deliberate move towards multi=centered urbanism is inevitable in the age of post globalizing world, the need for an urban human scale and the challenges of postCarbon paradigm.
\end{abstract}


Metropolitan Doha, Urban Resilience, Doha Sustainable Development, Transit Oriented Development.

\section{Resilience in Urbanism and City Planning}

\subsection{The Conceptual Discourse}

The holistic understanding of urban resilience resonates with the Sustainable Development Goals (SDG) as compiled by the UN Habitat. Particularly, goal 11 suggests the importance of creating inclusive, resilient, sustainable and safe cities. This paper provides an overview of the development of the resilience concept in the domain of urban development and planning. Over the last two decades the concept of resilience has experienced escalating interest. However, due to a lack of consistency in defining and measuring this theoretical construct within and across disciplines, the recent explosion of literature on resilience has contributed more to confusion than clarity among researchers and policy makers. The notion of resilience is gaining increasing prominence across a diverse set of literatures on cities and climate change. Although there is some disagreement among these different literatures about how to define and measure resilience, there is broad consensus that: (1) cities must become resilient to a wider range of shocks and stresses in order to be prepared for climate change; and (2) efforts to foster climate change resilience must be bundled with efforts to promote urban development and sustainability (Leichenko, 2011). Resilience is the ability of a system, community, or society exposed to hazards to resist, absorb, accommodate to, and recover from the effects of a hazard in a timely and efficient manner (Jha and al., 2013). (Pizzo, 2015) problematizes the introduction of the concept of resilience into the planning domain from three main starting points: 1 . The nature of the events which are said to require resilience; 2 . The different nuances in meaning that resilience assumes according to those different events, and 3. The theoretical and operational problems the concept entails. The paper sustains that multiple sub meanings are embedded within one interpretation of resilience that leave the concept open to rather large margins of ambiguity, which emerge considering its operationalization. The concept seems to fit and to be appropriate within different paradigms, planning traditions and policy frameworks. Its alleged 'neutrality' is one of the main reasons of its pervasiveness, but also of its ambiguity, showing latent controversial implications, which are progressively emerging in critical planning theory. Hence, the interpretation of holistic urban resilience should start with the people and their social dynamics. Here, the notion of the interaction between the people and the city should be based on concepts like just city and cities for all without any form of segregation or marginalization.

Hence, the paper calls for a need to revisit the concept and its utility to the prosperity of cities. However, resilience has been closely associated with sustainability for more than a decade, although without precise meaning and often as an additional label attached to preexisting research (Timon, 2014). Urban resilience is a broad concept that is sometimes blurred and abstract. Part of the effort to render the concept to a clearer interpretation is first to assert that Urban resilience addresses adaptation as well as mitigation. It is associated with spatial planning policy-making in the context of different levels and forms of uncertainties. Therefore, urban resilience provides a new way of framing and responding to uncertainty and vulnerability. Considering this interpretation, urban resilience offers an alternative paradigm for planning strategies. 

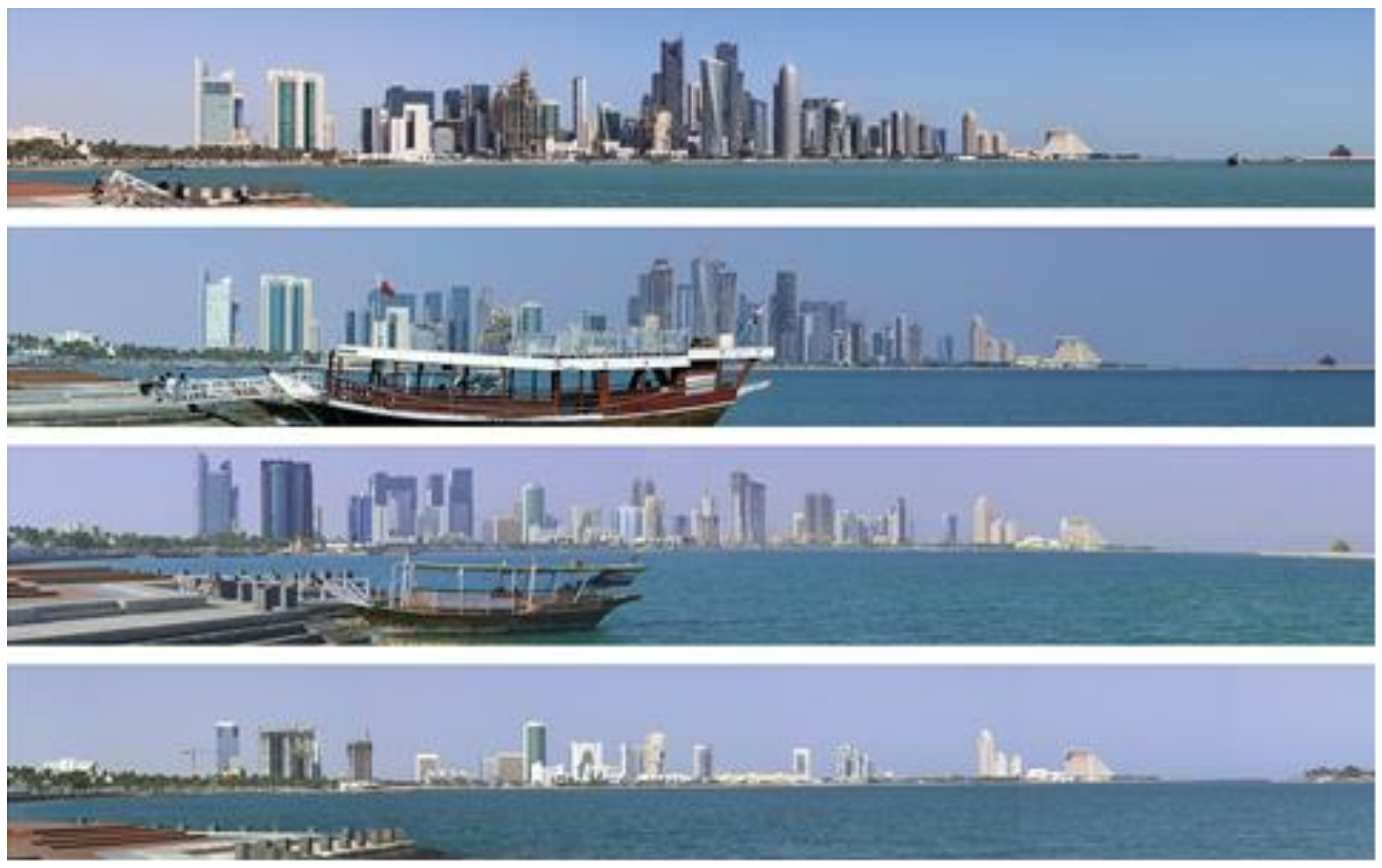

Figure 1 The urban growth of Doha witnessed unprecedented rates due to the use of oil revenues in reshaping the image of the city at the end of the twenties century. The city moved through a decade of change from 1995-2005.

\section{The Narrative of Qatar: Qatar's Context and Territorial Background}

\subsection{The Contextual Understanding}

Qatar is a peninsula in the east of Arabian Desert and covers an area of $11,437 \mathrm{~km} 2$, with a coastline of $563 \mathrm{~km}$. The country is a mostly low-lying and flat stretching into the Gulf from the lands of Saudi Arabia. Until few decades ago, Qatar was dominated by nomadic people whose livelihood depended on fishing and pearling. However, the discovery of oil and gas has encouraged not only socio-economic changes, but urban and environmental changes as well. The newly acquired wealth and associated development have not come without challenges. Since 1984 the population has grown from just under 350,000 to 1.5 million in 2008 and to over 2.2 million in January 2015 (Qatar Statistics Authority, 2015). Qatar's overall population witnessed unprecedented increase since 2010 after the declaration of the State's wining a bid to host the FIFA world cup 2022. The current population is 2.5 million, of which only around 15 percent are native Qataris. Today, the capital, Doha is home to more than $90 \%$ of the country's 2.7 million people, the majority of whom are professionals from all around the globe (QSA, 2015). Up to the mid-1960s, the majority of Doha's built environment was composed of traditional houses that represent local responses to the surrounding physical and socio-cultural conditions. During the 1970s and 1980s Doha was transformed into a modernized city because of extensive use of oil revenues in modernization projects particularly housing, infrastructure, roads and community facilities. 


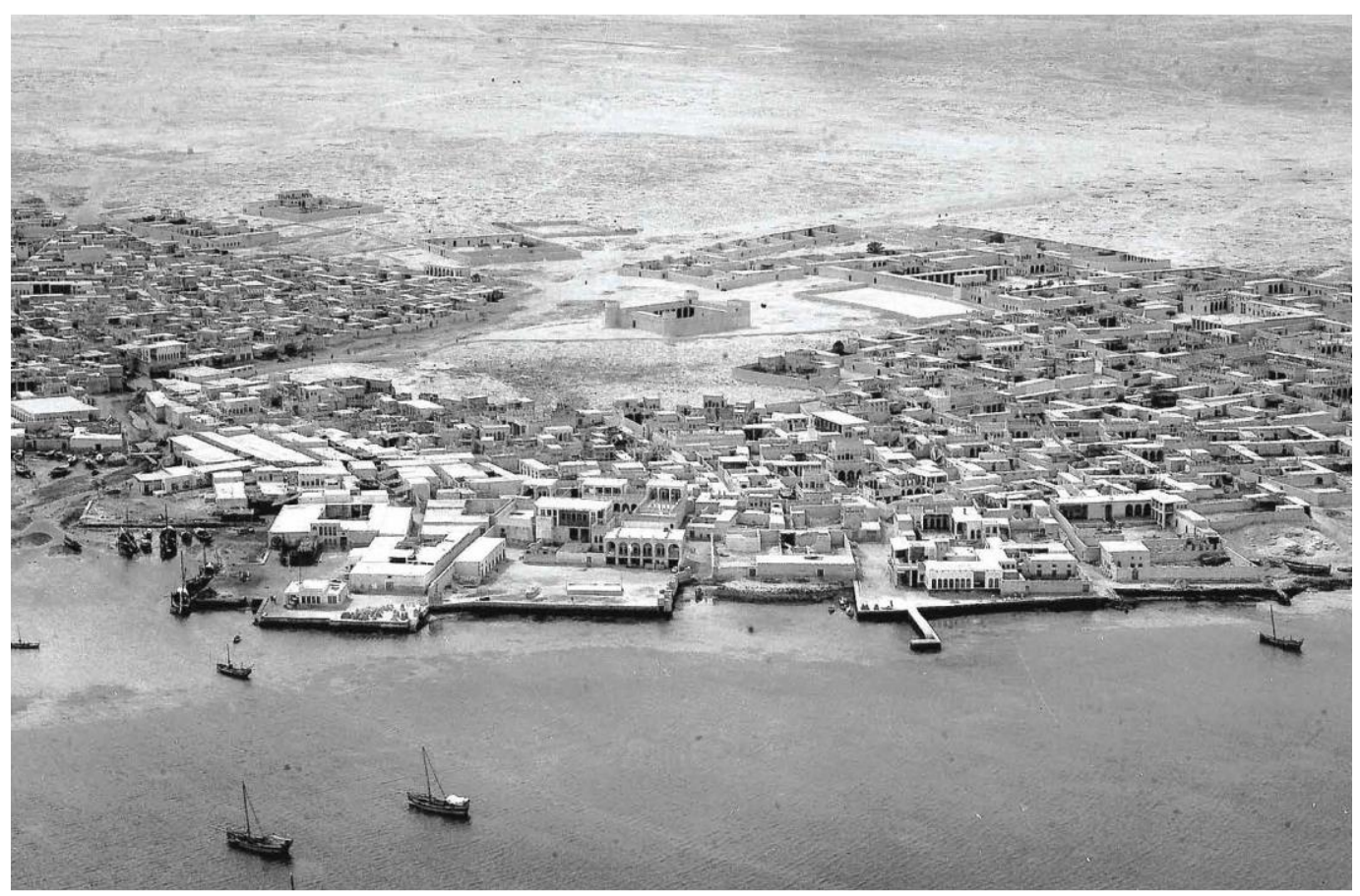

Figure 2: An aerial photo captured in mid-forties showing Doha's waterfront, AL Jessra Area, the cemetery and Al Khot Fort (Source: Ministry of Municipality -MME).

\subsection{The Post-Independence Paradigm}

Qatar was under the British Protectorate from the year 1916 and gained independence in 1971. Since that time, it has been going through tremendous growth in different sectors. This growth has mainly been facilitated by the country's massive oil and natural gas reserves. The revenues have been used to streamline sectors such as health, construction, education, financial, and manufacturing. Conditions for doing business are friendlier as there is no income tax and corporate tax for domestic firms, but only foreign firms are charged a $10 \%$ corporate tax (Almfraji, Almsafir, \&Yao 2014). Qatar is currently ranked among the highest GDP capita globally. The country has continuously experienced a high level of economic growth, averaging to 25.4\% between the years 2004 and 2012 (World Bank, 2013). The economy in Qatar is diversified into various sectors, all of which contribute significantly towards achieving the growth of the country. Even tourism, especially in the last decade, is becoming one of the main platforms for diversifying Qatar's post-oil economy (Phelps, 2013). Over the past decade, Qatar has become one of the major world producers and exporters of Liquefied Natural Gas (LNG). The wealth produced by Qatar's oil and gas exports has generated a construction development boom in the capital, Doha, and the surrounding vicinity. This resulted in significant growth at all levels from urban development and infrastructure provision to cultural, recreational, health and educational facilities. 


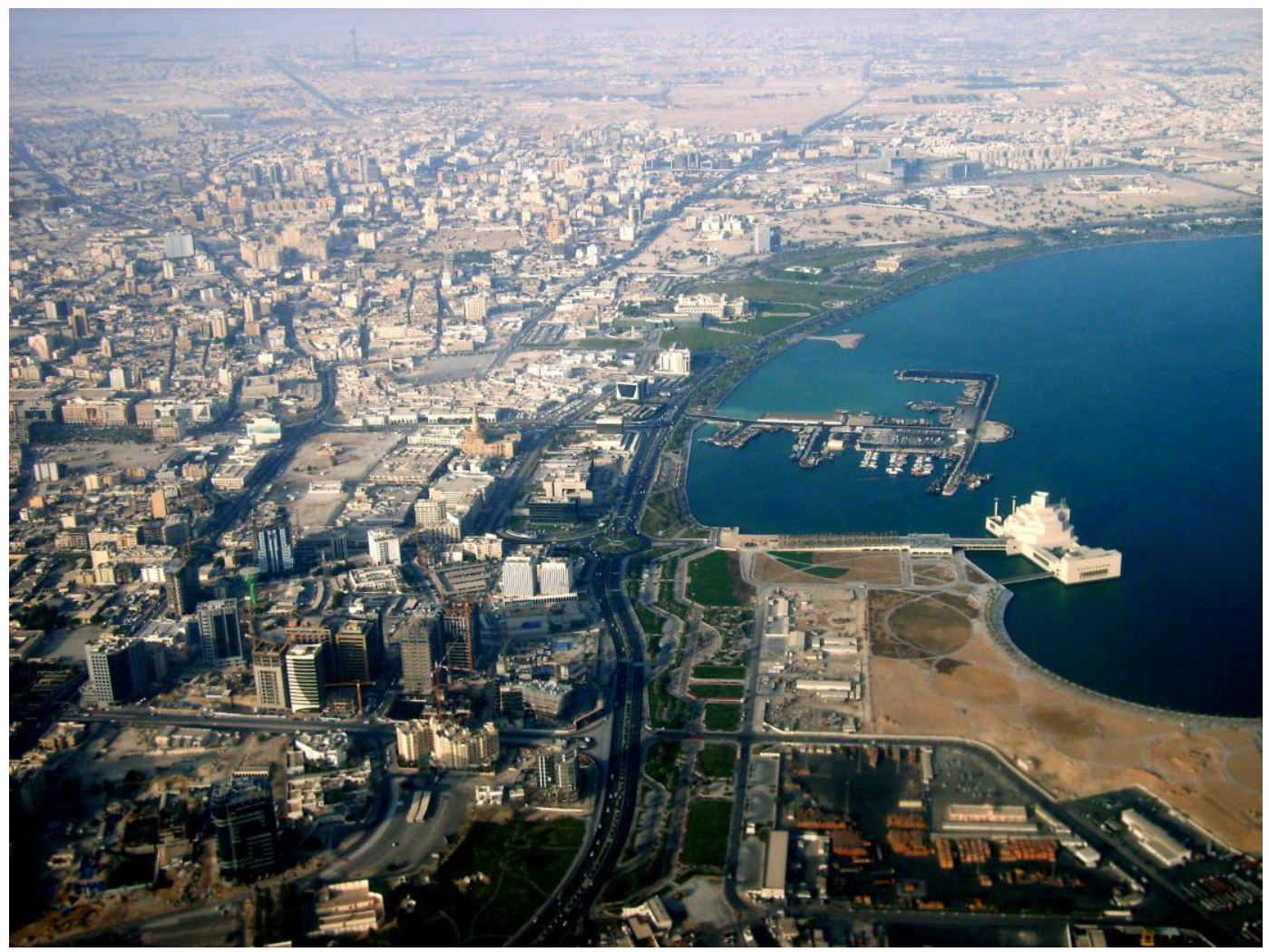

Figure 3: The patterns of accelerated growth in Doha resulted in uncontrolled urban sprawl which created a major challenge for the city's urban future.

\subsection{Moving Towards Knowledge and Creative Economy: From Oil to Knowledge}

Qatar has embraced the idea of developing a knowledge-based economy and successful steps have been implemented. One example of this is the support of human capital development in the founding of the Qatar Foundation in 1995 with a fund of $\$ 2$ billion and in 2009/10, education accounted for $13 \%$ of government expenditures. Qatar Foundation supports education, research, capacity building and open dialogue at all levels, supporting activities such as the Doha Debates and Al Jazeera television station. Al Jazeera, an overwhelmingly successful Arabic language news channel, has provided a forum for open discussion and criticism. In terms of Qatar's National Vision 2030, the security of the peoples' standard of living is to the fore, but the government realized that this cannot be the main and only goal of a country. With the focus on its values, Qatar has to balance some further challenges: modernizing traditions while ensuring their preservation, serving the needs of this and future generations, managing the country's growth and expansion, controlling the targeted size and the quality of the expatriate labor, going a path of development that is compatible to it, managing the economic growth and the social development and protecting the environment (J. Gremm et al., Transitioning Towards a Knowledge Society, 2018). To resolve these challenges and to fulfill the transformation of Qatar into an advanced country until 2030, the government outlines and promotes four pillars that the Vision rests on. 
Qatar leaders are convinced that post oil paradigm is becoming a reality. Hence, moving from industrial economy to knowledge economy is a global and inevitable transformation which requires understanding and better engagement. Therefore, Qatar National Vision 2030 (QNV) was articulated to construct a roadmap for the alternative future of the State. The vision outlines the development of Qatar over the next twenty years. The QNV 2030 is based on four supporting themes: human development, social development, economic development and environmental development. To facilitate the realization of QNV, Qatar is positioning itself as a knowledge-based society, principally in the fields of education, research, energy and technology. Qatar is determined, due to its awareness of the swiftly arrival of the post carbon era, to diversify its economy and go beyond the total reliance on oil and gas. The plan is to educate and train nationals properly to pave the way to a global knowledge society. This proves that the willingness to pursue the status of a knowledge and creative city definitely exists. According to Stephenson and Al-Hamarneh (2017) despite the fact that Qatar has been rapidly modernized, it has not enough developed to be considered an international tourism destination. Nevertheless, hosting mega events like the 2022 FIFA World Cup will motivate Qatar to work on developing different tourism types such as ecotourism. For this reason, Qatar has established and developed different ambitious goals of tourism development by adopting a strategy called Qatar National Tourism Sector Strategy 2030 in the year 2014.

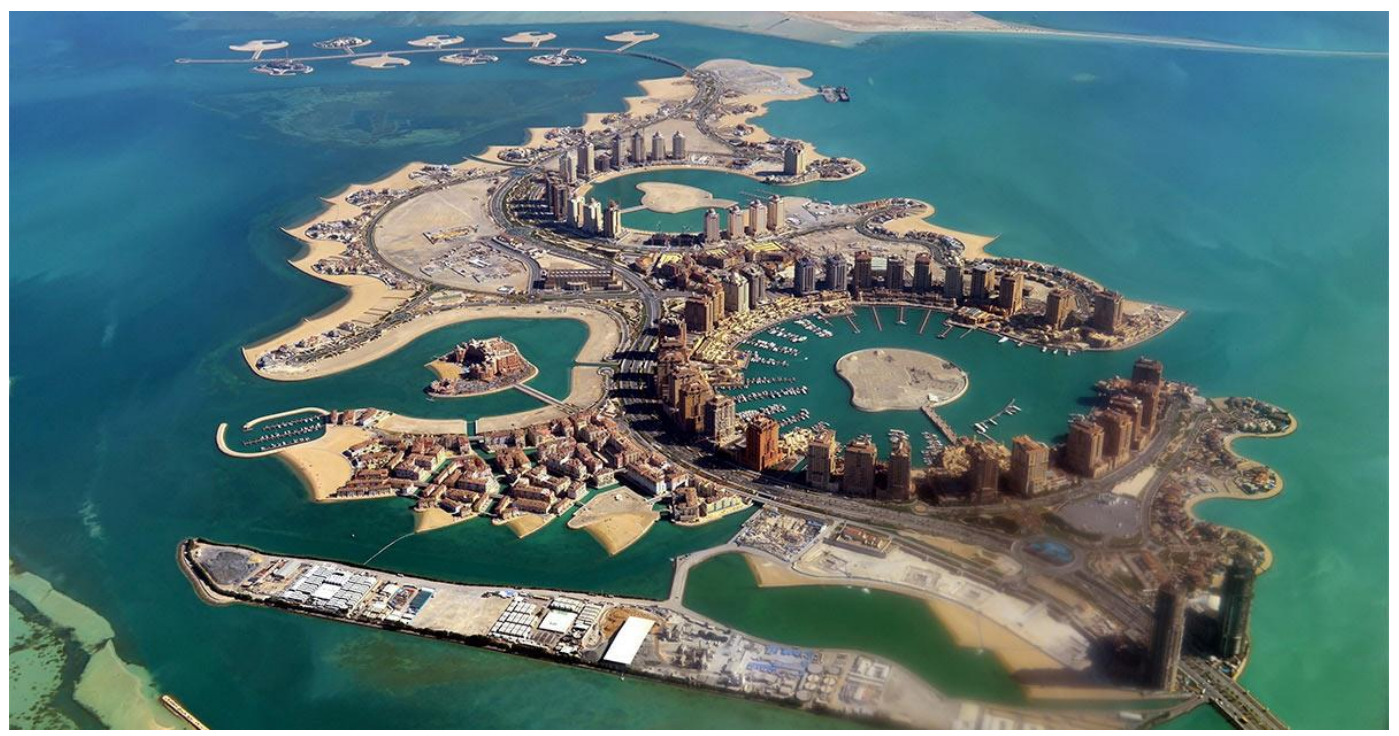

Figure 4: The iconic development in the real-estate sector which characterized the pace of development in the beginning of the third millennium as a reflection of globalization.

\section{Towards a Holistic Urban Planning Framework}

\subsection{Subheading 3.1}

Through the wise insights of His Highness Sheikh Hamad Bin Khalifa Al-Thani, Father the Emir (AIAmir AlWaled), a National Vision (Emir Decree No. 44 (2008)) has been prepared to set out the long-term direction for the country, to inspire its people and to develop a set of common goals related to their future. 
"The National Vision aims at transforming Qatar into an advanced country by 2030, capable of sustaining its own development and providing for a high standard of living for its entire people for generations to come." (QNV, 2008). In December 2006, Pacific Consultants International ( $\mathrm{PCl}$ ) provided a proposal for Qatar National Master Plan (QNMP). The suggested QNMP was needed to cope with the long-range strategic vision of Qatar. The physical development was not only considered but also economic, social, cultural and environmental factors and challenges were included and confronted to guarantee the comprehensiveness of the proposed plan. Consequently, the Oriental Consultant (OC) was hired to prepare a comprehensive urban plan for Qatar. QNMP is to guide urban development for the State over the next 25 years. And comprehensive development scheme is the main tool that will benefit all segments of society. On a strategic level and to translate QNV 2030 and other national policy directions into physical and spatial development plans, policies and actions for implementation, a structured process was used to prepare the Qatar National Development Framework (QNDF). The QNDF provides the framework for managing growth, change, land use and development in Qatar to 2032. The QNMP is the spatial representation of the QNV2030. The QNDF sets the strategic framework for sustainable development and provides plans for the country, for Metropolitan Doha and for the Municipalities that make up the nation's principal administrative structure (QNDF, 2016).

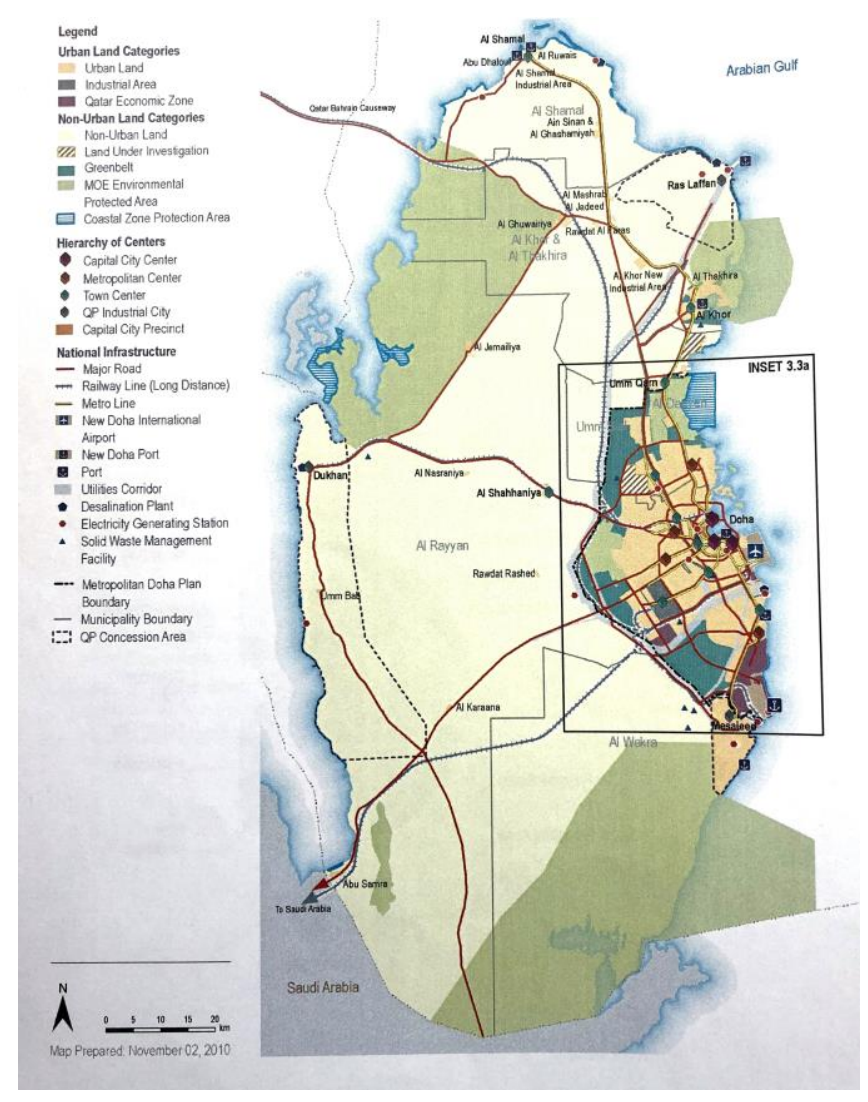

Figure 5: Qatar national spatial strategy 2032 where Metropolitan Doha is subdivided using the concept of hierarchical urban centers (Source: QNDF, MME). 


\subsection{Contesting Doha's Model of Resilience}

In this section, an analysis of the most dominant forces that challenged the development of Doha city in the last decade will be provided. Hence, all the strategies, processes and policies which were adopted by the city will be shared to illustrate the city's resilience model. Interestingly, some of these dominant forces were celebrated like winning the bid to host the 2022 FIFA World Cup, while other were a substantial shock and have created a seismic impact on the city's people, economy and development. Doha was alert for the critical need for a flexible and dynamic approach to building resilience that goes beyond risk mitigation. Therefore, in the coming sections, three main challenges will be narrated and Doha's answer to each of them will be illustrated. Three milestones which are representing the most alarming challenges that Doha have faced in the last decade, analyzed in a chronological order. The analysis provided illustrates the wider interpretation of the challenges which require a resilient plan. The notion of city challenge is also extended as it doesn't all the time implies negativity. Cities need resilience also to deal with positive challenges facing its development and progress. Therefore, the milestones analyzed go all the way from economical threats, hosting a global event to a comprehensive blockade.

\subsection{The Inevitability of the Post-Oil Paradigm and the Urban Planning}

A major challenge which the paper addresses is the fluctuation of oil prices and how Doha is structuring a vison for the city in the post-carbon paradigm. Such a paradigm implies a move from oil-based economy to a knowledge-based economy and how to plan the city to facilitate such a new economical paradigm. With an unprecedented financial resources, creative strategic thinking and political commitment, Qatar is constructing a new development and urban brand; Dohaization which is a brand but also a continuous dynamic process. The case of Doha is stimulating as new mega projects are made to pave the way for a new development vison structured upon the value of knowledge economy and knowledgebased urbanity. By any measure, Qatar's growth is phenomenal; in the past decade the population has trebled, and the size of metropolitan Doha has increased fourfold. From its humble origins as fishing and pearling village, Doha has emerged as an expanding world city, where ambition and means are fuelling exciting experiments in education, health, sports and culture (Framherz, 2012; Jodido, 2014; Alraouf, 2016).

For a better understanding of how Doha came to structure its current identity, an investigation into the State's main strategy and the articulation of Qatar's role regionally and internationally is crucial. In this section, we will discuss the State's main strategies which affected the development of Doha. The Paper sheds light on the concept of Doha's attempt to construct a new identity which transcends the model that was created by Dubai's iconic development and real-estate fantasies. Then, the notion of knowledge economy as adopted by the State and clearly articulated in QNV 2030 will be analyzed to illustrate the quantitative and qualitative shift towards knowledge-based urban development in Doha. Evidently, in the last decade a new pattern of planning interventions can be clearly observed in the urban fabric of Doha. These new interventions described as the city's mega projects due to its size, location, population served and visual and urban impact. 


\section{Beyond the Metropolitan}

\subsection{Deconstructing the Metropolitan: Introducing Hierarchical Urban Centers}

Doha's future urbanity is crystalized around the move from centric to polycentric urban planning. One of the most significant strategies adopted to deconstruct the metropolitan extended boundaries which was created during the years, is based on introducing the concept of hierarchical, vibrant and livable urban centers. The centers were planned to have certain common attributes that are summarized as follows: The appropriate density, the distance between land uses and community needs, the diversity represented in the mixeduse developments and finally the design and place making approach which would focus on public spaces, streetscapes and the ability to accommodate multiple forms of transportation. The significance of the previous attributes is manifested in the urban independence of such center in proportion with the relevant community it serves. More importantly, centers planned as such facilitated introducing the concept of transit-oriented development (TOD) and the move towards reliance on public transportation. Evidently, the future growth of Doha includes multi urban centers. In addition to their strategic locations, the relationship of these centers to each other and to their service catchments in a hierarchy and the mix of uses that exist or can be guided to each center in the future are major elements of the QNDF National Spatial Strategy.

As clearly explained in the QNDF, the hierarchy of centers was identified using a sequential strategic assessment based on five key criteria:

- Level of existing population and employment density, economic investment and infrastructure.

- Level of existing Government/Municipality office and community facility provision.

- Potential accessibility to the future strategic transportation Network.

- Proximity of committed mega projects or other major Government developments including Qatari national housing schemes.

- Availability of vacant land and potential for regeneration or urban infill.

This hierarchical structure promotes mixed-use, mixed density centers and enables more efficient and equitable use of national level investment in transportation and utility infrastructure, which in combination, provide the sustainable development pattern that the QNV2030 strives to achieve (QNDF, 2016 P.40).. 


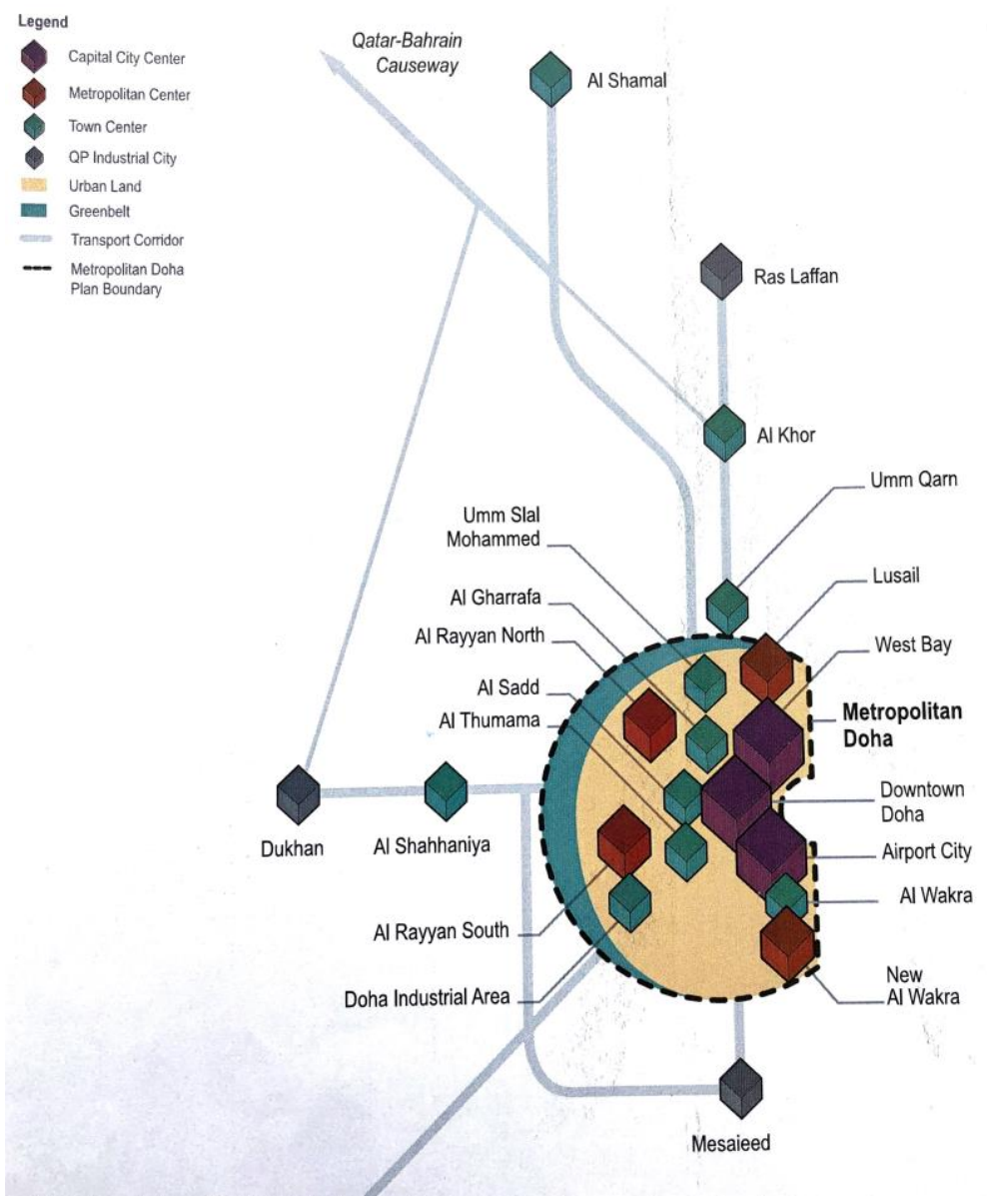

Figure 6: The Spatial Strategy Concept 2032 indicating the location and hierarchy of urban centers.

\section{Less is Beautiful: Strategies to move beyond the Metropolitan}

\subsection{The Transformation from Car-dependent Sprawled Urbanity to Transit Oriented Development (TOD)}

The Qatari society is in dire need to move from a car-based development to a TOD approach for the urban growth. The future plans adopted set of actions and policies to gradually encourage the needed transformation. These policies include; Vibrant Metro Stations, Accessible Public Transportation, Streets for People not Cars, Water Transportation and Connected Bike Routes. The aim is to establish a high quality and integrated public transport network that results in a modal shift from private motor vehicles to public transport across Qatar. Additionally, to ensure radial routes act primarily as public transit corridors designed to reduce private motor vehicle usage and environmental costs and promote orbital routes to aid the creation of balanced growth. For a more effective transit-oriented development and pedestrian-friendly cities in Qatar, a comprehensive plan to encourage bicycle riding was also prepared. The Qatar Bicycle Master Plan suggested the proposed Greater Doha bikeway network. Three categories of routs were suggested; green (Bicycle Paths) for recreational, blue (Cycle Tracks) for major transportation and red (Bicycle Lanes) for local transportation 
(see map below). The form of urbanism which was produced during the availability of lucrative oil revenues was predominantly car-oriented urbanism. The whole process of Doha evolution was characterized by unlimited urban sprawl due to the population increase and the dominance of a single-family house as the only form of housing for Qatari families. These patterns of urban growth facilitated the unprecedented investment in roads network which can connect all such scattered urbanism. Hence, singles or Families, locals or expatriates consider private vehicles as the only form of transportation. While the local bus services company, Karwa, provides well-distributed routes all over the city but with the availability of cars, the cheap gas and lack of positive culture of walkability, people opt to use their cars in all their daily activities from going to work, dropping their kids at schools, buying groceries and recreation activities. More significantly is the social barrier towards public transportation as it becomes gradually associated with workers and low paid expatriates. On the other hand, Qataris were considering using public transportation in the form of bus riding as a social degradation and inappropriate behavior. With such background, the introduction of Doha's new metro will create a substantial change. The metro which is composed of four lines covering all of Doha's main destination and connecting the city with the airport, universities, industrial area, cultural facilities, shopping centers and main residential areas would be seen as an excellent solution for both locals and expatriates particularly giving the fact that commendable effort were invested to create state of the art transportation experience in the metro' stations, compartments and trains. The stations and trains are designed to accommodate the peculiarities of the cultural and social context of Qatar by providing privacy for families and women in designated sections of the trains.

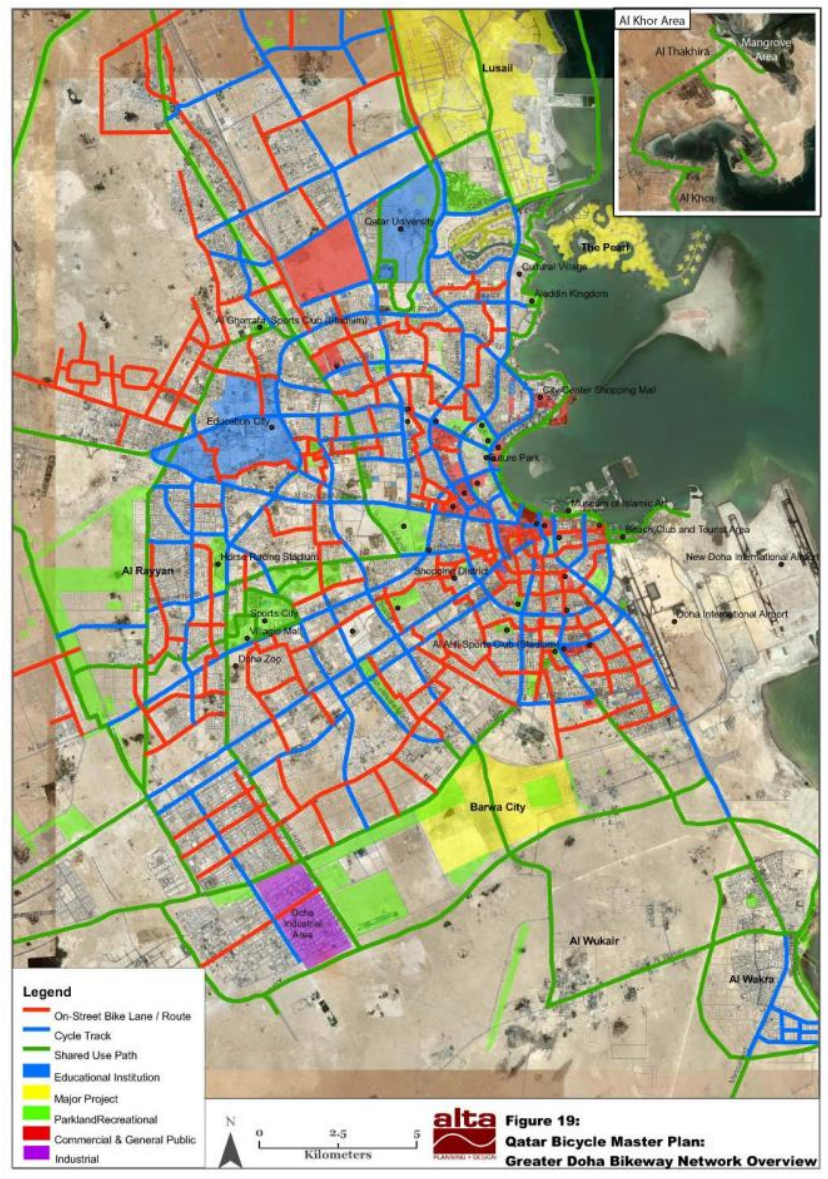


Figure 7: The Greater Doha Bicycle Network is based on three categories of Bicycle movement; Green: recreation, Blue: major street transportation and Red: local street transportation (Source: Ministry of Transportation).

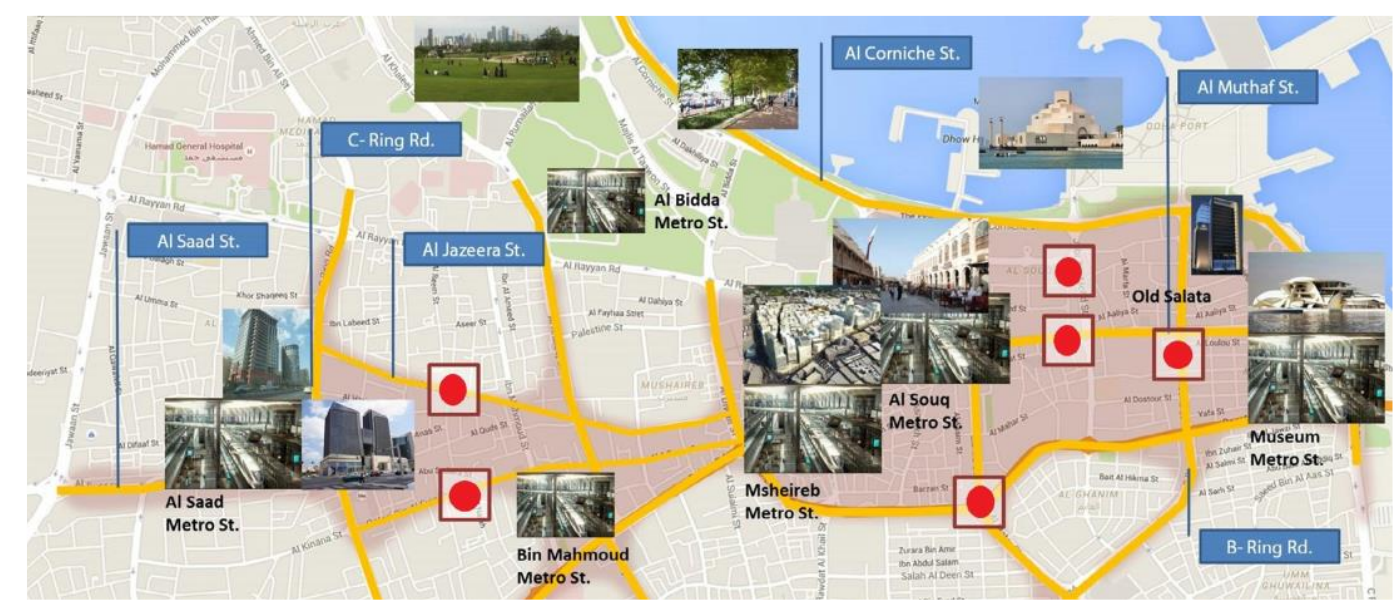

Figure 8: The relation between metro stations and mixed use urban centers as a strategy to decentralize Doha and move towards small and compacted form of urbanity (Source: MME).

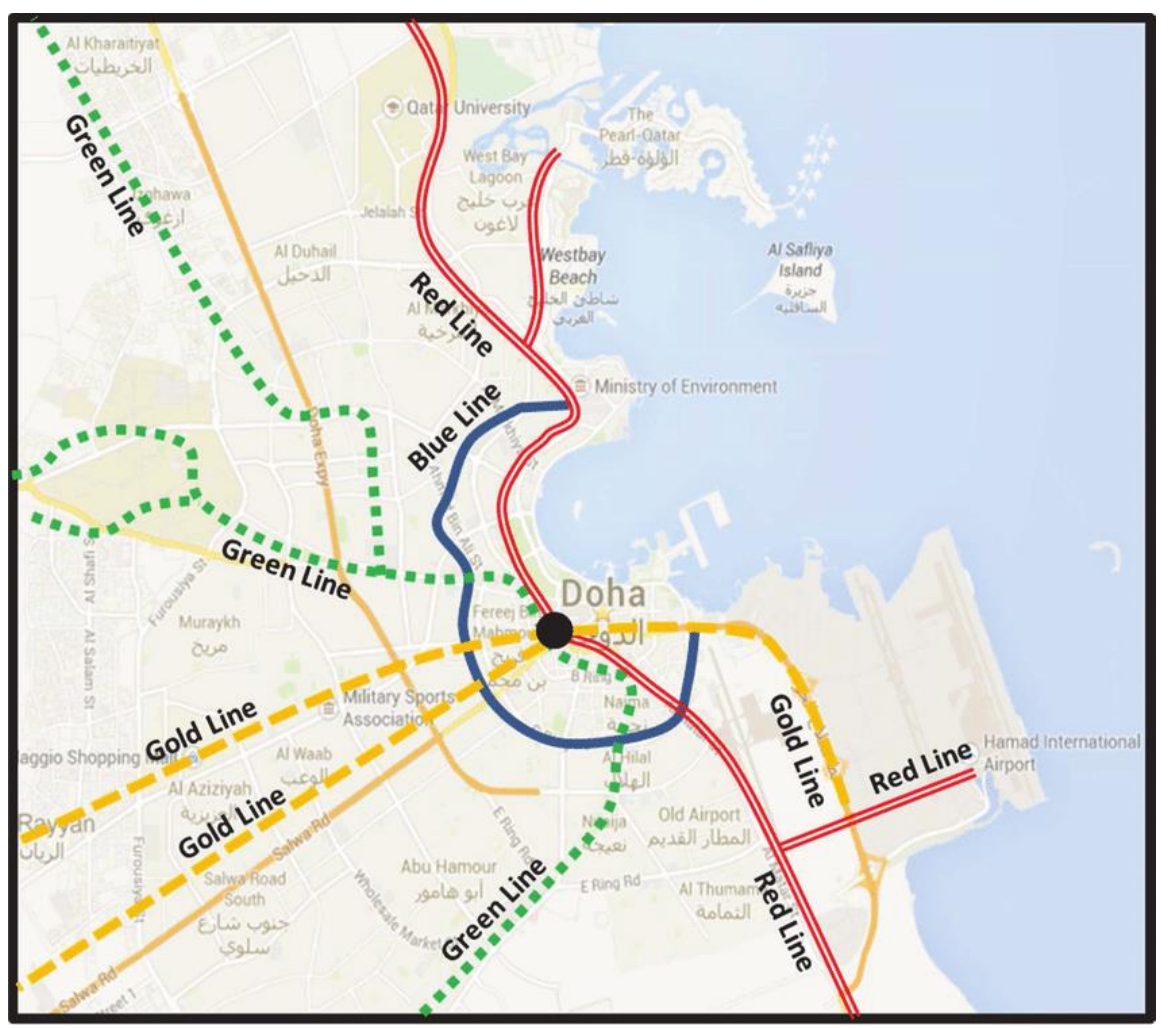

Figure 9: The post-oil urbanism suggests a paradigm shift towards walkability and transitoriented development in Doha and hence Doha Metro is introduced as a main from of transportation in future Doha. 


\section{Encouraging Walkability and Livability}

One the direction of urban development in Doha moved from horizontal expansion and unlimited sprawl to a multicenter urbanity which is based on the needs of the community, new values are injected in the Doha's urban scene. The principal two values introduced to the city of Doha are Walkability and Livability. Both are so interrelated and substantially support each other. To enhance livability, an emphasize on the social life in public space is becoming a priority. Public spaces -particularly lively streets and squares- among buildings enhance livability and help to animate the neighborhood. Open spaces have the role to make people passing near or stopping by and feel them welcome. Introducing the culture of walkability in Doha and doing the needed steps to have a truly walkable community, number of actions have to be made. Encouraging people to walk in the city requires positive infrastructure which includes wide vibrant sidewalks, nodes of commercial and recreational side activities, footpaths, safe pedestrian crossings exciting and informative signage, creative street furniture and more importantly shaded areas resulted from landscape features like tress or artificial elements like wooden or textile pergolas. Schemes to enhance public realm, streetscapes, open spaces, small parks or shaded town squares. The urban planning department in Qatar (UPD) is conducting a number of projects and studies to achieve these aspirations including the National Strategy for open and recreational Spaces, The National Urban Design Compendium, Streetscape Design Guidelines and National Landscape Guidelines for Vibrant Streets.

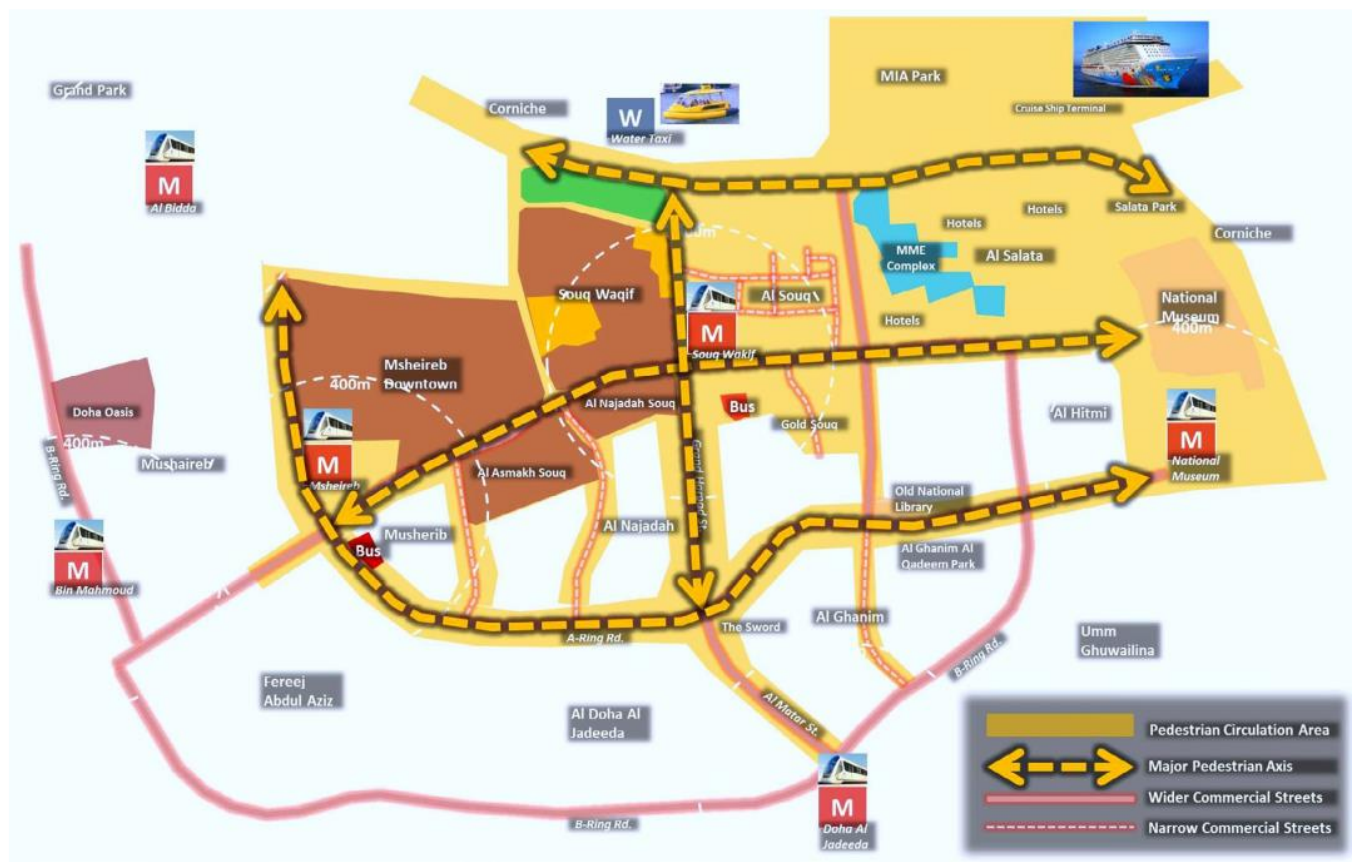

Figure 10: The different levels of connectivity which allow for an integrated and not fragmented urbanism. 


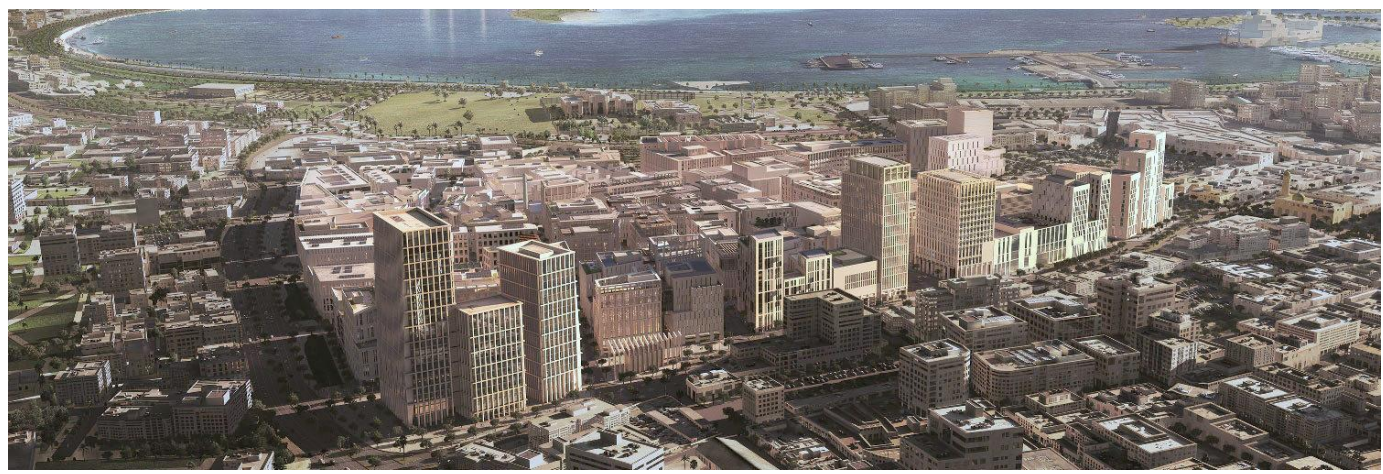

Figure 11: Msherieb project as a catalyst for a new foprm of mixed use, walkable, livable and sustainable development creating a suburban center within the city fabric.
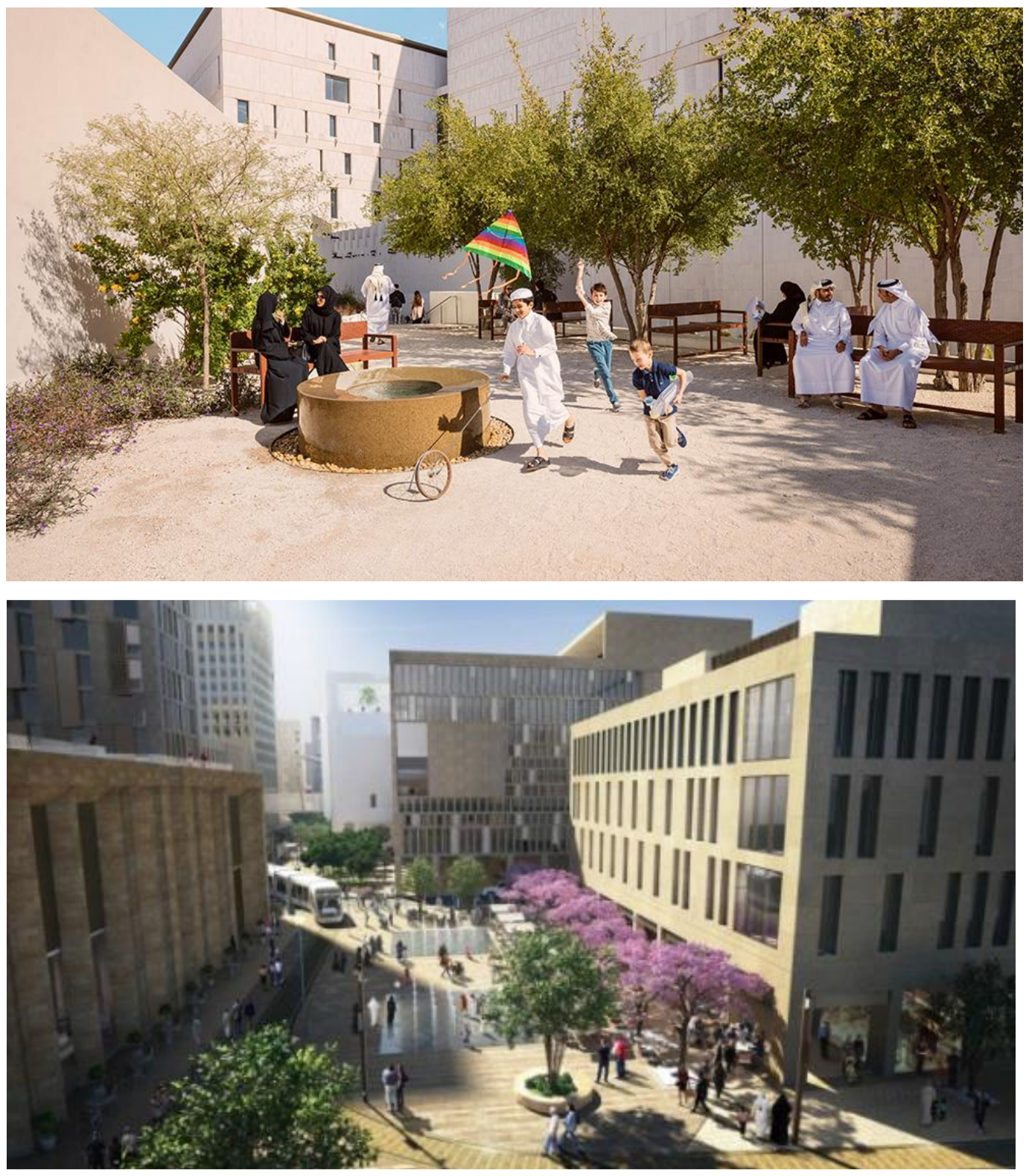

Figure 12 \& 13: Creating Pedestrian friendly environments to encourage the shift towards walkability and vibrant public spaces (Source: Msherib Properties). 


\subsection{Doha as a Network of Knowledge-based Urban Development Centers}

In a post carbon paradigm, Qatar's identity is articulated around the notions of knowledge, research and education. Qatar National Vision 2030 is a development strategy which outlines how Qatar will use the vast revenues from its hydrocarbon resources to transform itself into a modern knowledge-based economy. Within this understanding, the Doha's future was envisioned as a manifestation of the country's future vison. Hence the following actions were adhered: Engaging people in knowledge experiences, constructing an Urban Campus; a creative and inspiring urbanity and Establishing a Network of Museums, Galleries and Cultural Centers. Currently, Doha is considered by many indicators as the most advanced city within the Middle East to adopt knowledge economy as a conceptual base for its 2030 vision. Qatar did a radical transformation to go beyond the typical image of a Gulf city relaying on presumably endless assets of oil and gas. A move towards being a regional center for education, knowledge and culture is the new aspired sense of identity for the Gulf State. A major investment in knowledge-based urban development characterizes major projects in the country during the last five years (Alraouf, 2008; 2014). This new identity of Qatar paved the way for a new paradigm in Doha's urbanity which can be best described as the Knowledge-based urban Development Paradigm. Qatar has become a showplace for renowned architects, several U.S. universities have established campuses there, and it will host the FIFA World Cup in 2022. The quantity and the quality of architectural and urban projects which will be added to the city's urbanity to facilitate hosting the 2022 FIFA World Cup would make Doha a very unique world destination. Significantly, Doha has gained global significance through the growth of knowledge economy related projects. The city's new urban development and its spatial qualities contribute to the global attractiveness of Doha for knowledge economy investments, firms and people. Such urbanism fulfills the requirements of Knowledge workers coming to the city from literally every spot of the globe anticipating an attractive smooth quality of life which would foster their creativity and innovation. With increasing awareness about the carbon emissions and the negative impacts of climate change, the paper evaluates Doha's attempt to transform its urban movement pattern from purely car-dependent city to a model for a transit-oriented development with the vitalization of connected network of public transportation, pedestrian streets and bicycle routs. Doha's model of urban resilience as reflected in the city's masterplan is answering the fundamental question of how to design and operate the city, so it can withstand major threats and how to recover from them? Yamagata and Maruyama (2016) argue that land-use planning and carbon-neutral scenarios for urban planning are fundamental tools in urban management leading to a better urban resilience. 

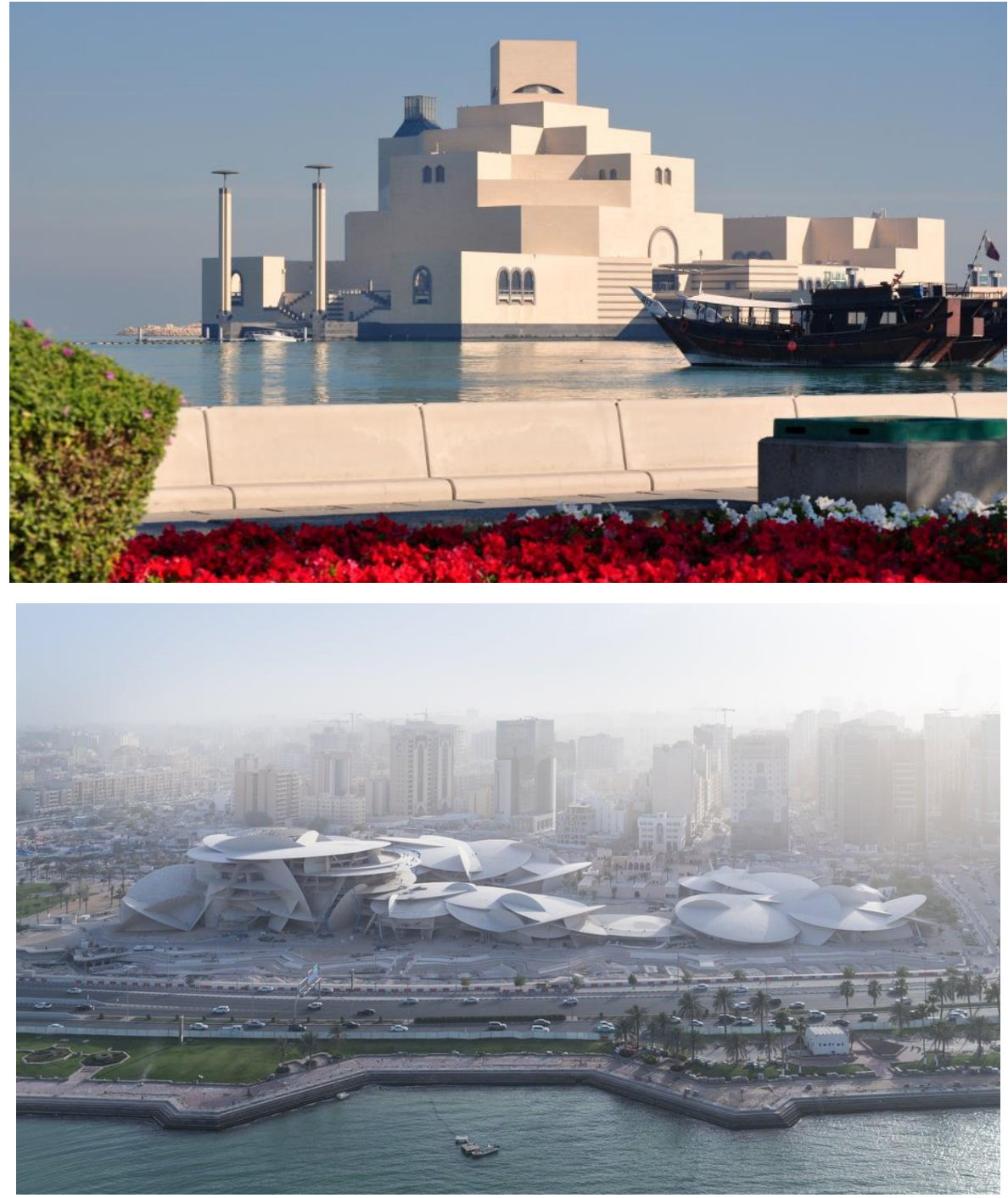

Figure 14 \& 15: The new cultural centers help Doha in establishing a new form of Knowledgebased Urban Development (KBUD); the case of Museum of Islamic Art and National Museum of Qatar.

\subsection{The Social Cohesion as a Catalyst for City Resilience}

Many scholars in the field of urbanism, through their research, have highlighted the importance of the human dimension in urbanism (Jacobs, 1961; Gehl, 2013) and offered insights into systematically studying environmental behavior (Zeisel 2006) through international studies in public life (Whyte, 1980; Gehl, 2013). Studying public life offers immense insights to urban environment professionals by bringing users back into focus when they may be overlooked in design (Gehl, 2013). The expected outcomes could play an essential role in achieving the needs of the visitors who are considered as tourists that would need to spend half of their day to explore the city. Baldwin and King (2018) emphasize that strong social networks and social cohesion can be more important for a community's resilience than the actual physical structures of a city. That what was exactly noticed in Doha after the activation of the blockade. More significantly, urban planning and design support these critical collective social strengths by stressing the necessity of creative spaces for all 
and enhance the inclusivity of the city's urbanity. In the process of realizing the goal of both sustainable and resilient development, we should see the dominant role of social factors such as urban governance in the process of urban adjustment and adaptation. The social aspect will be also addressed in the paper as Doha, like most of Gulf cities, has a muchdiversified population coming from all corners of the world. The urban future of Doha is planned to encourage inclusivity and transcend the concept of gated development and isolated urbanism. Hence, the social and cultural diversity was perceived as an asset. Planning Places for People, The Heart of the City is for All and Inclusivity as a Fundamental Development Base for the Whole city. More significantly, the city is taking a number of measures to create better connections between expatriates and the city significantly sense of belonging and ownership which would radically help in inspiring the city's overall population of locals and expatriated to better defend the city and take a solidifying position towards realizing its future aspirations. The paper concludes with articulating a more holistic framework for city resilience which takes into consideration the multifaceted nature of the city and better prepare it for different forms of changes and transformations which might occur in the future. Coaffee and Lee (2017) examine how the concepts and principles of resilience exert increasing significant influence over the form and function of planning. Their discussion of the 'politics of resilience' in which fundamental questions of social and spatial justice are posed is relevant to the notion of social cohesion in Doha after activating the blockade.

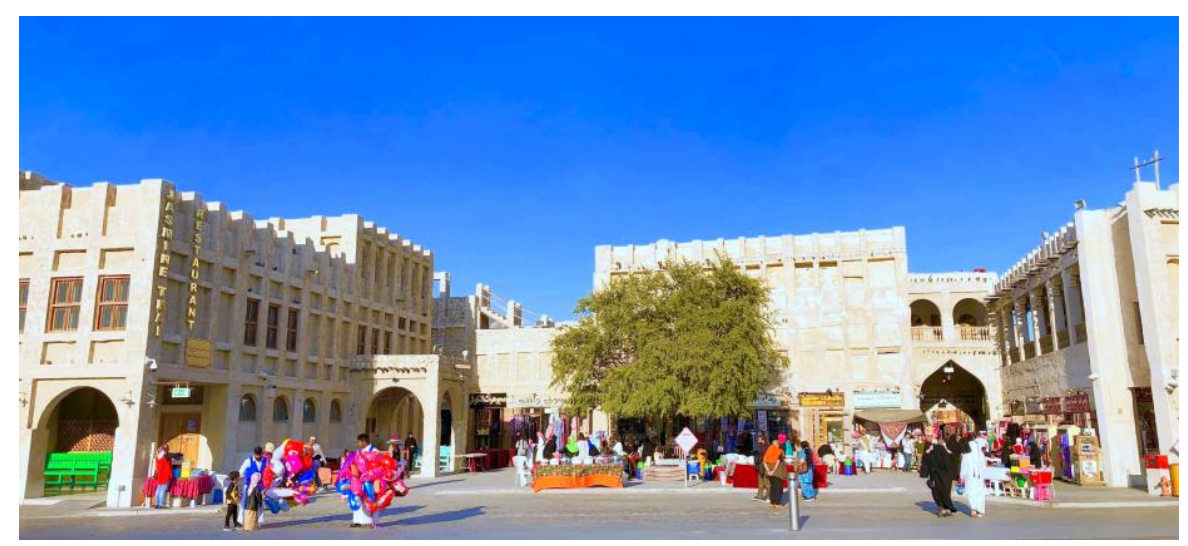

Figure 16: The city spaces are planned to accommodate the different social groups and emphasize the social cohesion.

\section{Conclusions}

As a conclusion, Doha's readiness for the post-oil paradigm can be perceived on three levels; strategically, urban planning and architecture. As explained in the earlier section, Doha is moving strategically towards a development vison articulated around the concept of the inevitable move towards knowledge and creative economy. On an urban planning level, Doha is moving towards a compacted model of urbanism by relaying on multicenter-city development to stop the unsustainable sprawl which was the dominating pattern in the last three decades. In addition, the city is activating a solid transit-oriented development approach to consider public transportation as the main mode of transportation within the city. Finally, on the architectural level, both Qatar Green Building Council (QGBC) and Gulf 
Organization for Research and Development (GORD) were established to produce, develop and monitor the implementation of green and sustainable architecture principles in the new buildings designed and built in Doha and all Qatari cities.

Intensifying the idea of a balanced social inclusion between major population sectors; the local citizens and working expatriates to create a sense of belonging, appreciation and recognition of mutual value and distinct roles of the country's rich human mosaic. Part of the city' success story stems from the fact that social cohesion was considered as a pillar in enhancing the resilience capabilities of the city. It describes and illustrates the ideas, tools, and tactics being used to help engaged citizens, civic leaders, and urban professionals to work together to build viable urban society. Also, adopting the principles of sustainability and environmental compatibility as the main pillars of development for Qatar National Master Plan (QNMP). ONMP is based on a set of sustainable urban development values like transit-oriented development (TOD), sustainable urbanization, social balance and the preservation of the historical and cultural identity. More significantly, dealing schematically and planner with major cities especially Doha as a framework for knowledge-based urban development through a network of research centers, universities, museums and the knowledge forums and make it available to all sectors of society in a way which would stimulate citizen and resident alike in a balanced manner.

The Future plans of Doha as described and observing its comprehensive impact on the city dwellers and visitors, cemented a paradigm shift in Doha's urbanity. The shift is based on the success of the project to introduce qualitative changes and new perceptions about the role of the built environment, historical urban areas, mixed use development, car-free planning and knowledge based urban development. The Planning of future Doha manages to adopt comprehensive inclusivity, which made the city for all a reality in all of its connected spaces. The project successfully and sensitively activated the heart of Doha and connected its veins. It is a success story, which resulted from adopting alternative planning approach, considering the environment, and more importantly allowing local communities and stakeholders to participate and gain an endless ownership.

\section{References}

Alraouf, Ali A. 2018. Knowledge-Based Urban Development in the Middle East. New York: IGI Global Publishing.

Alraouf, Ali. 2017. Interrogating Qatar's Urbanity as a Catalyst for Building Knowledge-Based Societies and Economies. In Bertelsen, Rasmus Gjedss; Noori, Neema; Rickli, JeanMarc (eds.) Strategies of Knowledge Transfer for Economic Diversification In The Arab States Of The Gulf. Pp: 53 -66. London: Gerlach Press.

Alraouf, Ali. 2016A. "Dohaization": An Emerging Interface between Knowledge, Creativity, and Gulf Urbanity. Pp.: 47-68. In Katodrytis, George and Syed, Sharmeen. Gulf Cities as Interfaces. Cambridge: Gulf Research Centre Cambridge.

Alraouf, Ali. 2016B. Museums as a Catalyst for a New Urban and Cultural Identity in Qatar Interrogating the Case of Museum of Islamic Art. In Museums in Arabia: Transnational Practices and Regional Processes.). Exell, Karen and Wakefield, Sarina (eds.) (Ashgate: UK, 2016). 
Alraouf, A. 2016. One Nation, One Myth and Two Museums Heritage, Architecture and Culture as Tools for Assembling Identity in Qatar. Representing the Nation: Heritage, Museums, National Narratives, and Identity in the Arab Gulf States, Publisher: Routledge, Editors: Pamela Erskine-Loftus, pp.79- 94.

Alraouf, A. 2015. Towards a holistic approach to sustainability: Heritage, architecture and culture as tools for assembling identity in Qatar. DOI: 10.5339/qproc.2015.qgbc.30.

Alraouf, Ali. 2012. A Tale of Two Souqs. In or Out of Place: The Paradox of Gulf Urban Diversity. Open House International Journal. Volume 37, Issue No. 2, June 2012. Pp:72-81.

Alraouf, Ali. 2008. Emerging Middle Eastern knowledge cities: the unfolding story. In Yigitcaular, T., and Koray, V., eds. Knowledge Based Urban Development: Planning and Application in the Information Era. IGI Global Publishing.

Baldwin, Cathy and King, Robin (2018). Social Sustainability, Climate Resilience and Community-Based Urban Development: What About the People? London and New York: Routledge.

Campbell, Kelvin. 2018. Making Massive Small Change. Building the Urban Society we want. London: Chelsea Green Publishing.

Coaffee, Jon and Lee, Peter. (2017). Urban Resilience: Planning for Risk, Crisis and Uncertainty. Palgrave Macmillan.

Cooke, Philip and Lazzeretti , Luciana (Eds.). 2018. The Role of Art and Culture for Regional and Urban Resilience 1st Edition. London and NY: Routledge.

Florida, R. (2012). The Rise of the Creative Class: Revisited. New York, NY: Basic Books.

Fromherz, A., 2012. Qatar: a Modern History. Washington, D.C.: Georgetown University Press.

Fromherz, A. J. 2017. Qatar. The Rise to Power and Influence. London, UK, New York, NY: I. B. Tauris.

Jacobs, J. 1961. The Death and Life of Great American Cities. New York: Random House.

Jha, Abhas K.; Miner, Todd W. and Stanton-Geddes, Zuzana (eds.). (2013). Building Urban Resilience: Principles, Tools, and Practice. Washington D.D.: World Bank Publications.

Gehl, J. 2013. Cities for People. Washington, DC: Island Press.

Gray, Matthew. 2013. Qatar: Politics and the Challenges of Development. Boulder, CO: Lynne Rienner Publishers.

Kamrava, Mehran. 2013. Qatar: Small State, Big Politics. New York: Cornell University Press.

Meerow, Sara, Newell, Joshua P and Stults, Melissa. 2016. Defining urban resilience: A review. Landscape and Urban Planning. Volume 147, March 2016, Pages 38-49.

Pizzo, Barbara. (2015). Problematizing resilience: Implications for planning theory and practice. Cities, Volume 43, March 2015, Pages 133-140. 
Qatar National Development Framework (QNDF). 2016. The Ministry of Municipality and Environment.

QSDP. (2011) (Qatar General Secretariat of Development Planning) National Development Strategy 2011-2016. Gulf Publishing and Printing Company, Doha, Qatar.

Qatar Statistics Authority. (2015). QSA Population. Retrieved February 22, 2015, from http://www.qsa.gov.qa/eng/populationstructure.htm

Roberts, David B. 2015. Qatar: Securing the Global Ambitions of a City-state. London: C Hurst \& Co Publishers Ltd.

Timon, M. (2014). The rise of resilience: Linking resilience and sustainability in city planning. Urban ecology at The New School in New York City, New York (2014).

Gremm, J., Barth, J., Fietkiewicz, K. J., and Stock, W. G. 2018. Transitioning Towards a Knowledge Society. Qatar as a Case Study. Cham, CH: Springer Nature. 